\title{
A REPLICABLE MODEL FOR VALUING LOCAL FOOD SYSTEMS
}

\author{
STEVEN R. MILLER* \\ Department of Agricultural, Food and Resource Economics, Michigan State University, East Lansing, Michigan \\ JOHN MANN** \\ Department of Agricultural, Food and Resource Economics, Michigan State University, East Lansing, Michigan \\ JUDITH BARRY \\ Department of Community Sustainability, Michigan State University, East Lansing, Michigan \\ TOM KALCHIK \\ Product Center Food-Ag-Bio, Michigan State University, East Lansing, Michigan \\ RICH PIROG \\ Department of Community Sustainability, Michigan State University, East Lansing, Michigan \\ MICHAEL W. HAMM \\ Department of Community Sustainability, Michigan State University, East Lansing, Michigan
}

\begin{abstract}
We use the underlying data of the IMPLAN Pro 3.0 regional economic simulation model to estimate the current economic contribution of Michigan's local food system and explore the chain of transactions giving rise to consumption of locally sourced goods from producer to processor to consumption. The proposed methodology includes both unprocessed and processed foods in the estimation of the local food system's economic value. The model also provides a replicable and consistent approach to estimating the value of local food systems within regional and state economies.
\end{abstract}

Keywords. IMPLAN, local foods, regional economics, simulation model

JEL Classifications. R15, R11, C88

\section{Introduction}

In response to an identified need for a more sustainable, equitable, and economically thriving food system, in which more people have better good food access, the Michigan Good Food Charter was developed (Colasanti et al.,

Funding for this research was provided by Michigan State University AgBioResearch, the MSU Vice President of Research Center Excellence Fund and the W.R. Kellogg Foundation. We wish to acknowledge the contributions of three anonymous referees and the editors of JAAE for their helpful comments and suggestions on an earlier draft of this manuscript.

*E-mail: mill1707@msu.edu

**E-mail: mannjoh3@anr.msu.edu 
2010). This charter was developed by industry stakeholders across the local food value chain and outlines a series of six goals, aiming to increase the amount of local food consumption coming from Michigan, improve profitability of farm businesses, expand urban and rural access to healthy food, enhance healthier food in schools, and improve education and entrepreneurship opportunities of K-12 students. More than 350 supportive Michigan organizations have adopted the vision that by the year 2020, 20\% of food consumed in Michigan will be profitably supplied by Michigan farmers. However, no substantiated measure had been demonstrated indicating what share of Michigan food consumption was locally sourced. This is an important metric for measuring the progress of the Michigan Good Food Charter toward reaching its goals. Using the method described subsequently, we estimate that in 2011 , approximately $17.7 \%$ of Michigan's food expenditures arise from Michigan producers.

The need to benchmark the economics of Michigan's local food system motivated this study. The approach demonstrated subsequently is equally applicable to other states and substate regions, allowing a level of comparability across regions. This is in contrast to existing studies that attempt to measure the economics of local food by means of surveys of direct-to-consumer sales through farmers markets (Bregendahl and Enderton, 2013; Brown and Miller, 2008; Hughes et al., 2008; Myles and Hood, 2010; Otto and Varner, 2005; Swenson, 2009) and community-supported agriculture (CSA; Brown and Miller, 2008), because such studies typically use multiplier analysis based on a measurable and verifiable volume of local food sales. Direct-to-consumer receipts is the principal direct measure of local food activity, to the exclusion of other, intermediated channels that local food takes (Martinez et al., 2010). The U.S. Department of Agriculture (USDA) has recognized the importance of such intermediated channels and recently announced new data collection efforts that account for indirect channels by which local food travels (Low et al., 2015). Such indirect sales to intermediaries may represent a significant portion of local food sales activity, and evidence suggests that farmers participating in local food supply chains through intermediaries increase their economic well-being compared with those that only sell directly to consumers (Low and Vogel, 2011; Low et al., 2015). Therefore, methods that capture the broader local food system economics are needed. We propose a more inclusive approach to measuring the local food system economics that accounts for all the channels by which local food reaches final consumption. The method is highly scalable down to the county level, allowing the analysis to accommodate differing views of what constitutes local food.

The significance of this framework is the simplicity of the approach that relies on evaluation tools readily available to agricultural economists. The approach affords a level of consistency across studies (regions within states or across states) and is inclusive of local food channels generally omitted from existing studies of local food systems. The study first develops a conceptual and empirical framework for valuing the local food system. Then, an empirical exposition using 
IMPLAN 3.0 is reported. We follow this with some caveats of this proposed approach and conclude by discussing the findings and challenges of this approach to estimating local food system economics.

\section{Background}

For the economist tasked with measuring a local food system, an ideal method for measuring the value chain of local food systems would be to trace transactions along the value chain. A shipment of foodstuff or a sampling of food items would be tied to a data logger that would record the volume, value, and location at each transaction. As the food progresses to a final destination, recordings of where transactions took place, performed processes, ingredient combinations from other data loggers, and the change in economic value through the supply chain would be registered. Such a system would determine how far up the value chain the tracked food progressed before final consumption and inform our understanding of food systems. For example, an apple sold at the local farmers market by the grower may have one data entry linking the farm to the sale of that apple. Alternatively, a processed apple may have three or more data entries, one registering the sale from the grower to the wholesaler, one from the wholesaler to the processor, one from the processor to the retailer, and one from the retailer to the consumer. Within each step, the data logger will record among others the value of the transaction, shrinkage through changes in volume, and the values of intermediary inputs like sugars, preservatives, cinnamon, and heat, all while recording the value-added contribution to each segment of the value chain. For an economist studying local food systems, such a system would change the narrative regarding the economics and regional economic growth potential of local food systems.

Ideal as such a method may be, it is hardly feasible given current technologies. However, it begs the question, do regional economists have the resources necessary to study the value chain to this degree? One common tool used by many regional economists may afford an analogous view of the value chain similar to that of the ideal data-logger model just described. The system of social accounting that underlies input-output models tracks the interindustry transactions within an economy, in which industries purchase goods from other industries as intermediary inputs to the production of final goods for trade and consumption. This system of accounting, as described subsequently, mimics this data-logging method in the aggregate.

Many readers may have been exposed to concepts of input-output models if they have read economic impact studies that purport a total economic impact in excess of direct changes in the economy. Input-output economics relate total economic effects as some multiple of direct activities, once accounting for all associated intermediate transactions. This approach is commonly applied to economic impact estimates of farmers markets based on receipts, in which 
secondary transactions are assumed (Henneberry, Whitacre, and Agustini, 2009; Hughes et al., 2008; McBratney et al., 2005).

Such conventional uses of input-output models to generate multiplier effects of farmers markets are effective at measuring the economic impacts of known values of economic activity. However, they fall short of measuring the level of economic activities tied to the much broader local food systems through intermediaries. Although farmers markets are the archetypical representation of local food systems, estimating the economic impacts of farmers markets, CSA enterprises, u-pick operations, and other representations of local food systems is limited to estimating the economics associated with these specific outlets. That is, measuring direct effects of the local food system through "key" local food channels would require measuring the value of transactions through each channel. Such a task would be a monumental accomplishment, requiring significant time and resources. The costs of such an endeavor would assure that such a measure cannot be replicated often, rendering this approach impractical for evaluating such things as region-wide local food promotion programs. In the end, it would still fall short of measuring local food purchases made through mainstream or indirect-to-consumer channels.

Alternatively, we propose a more comprehensive approach for developing baseline values of local food systems using software and data that are readily available for regions across the United States and specific to the county level. First, we will explore how input-output tables are structured and how this structure mimics the data-logging system described previously. We then use an example based on state estimates of the Michigan local food system. Finally, we describe weaknesses associated with the development of local input-output tables and its use for tracking local transactions, and we discuss potential approaches to remedy these weaknesses.

\section{Methods}

Although the structure of industry-by-industry input-output tables is well documented (see Miller and Blair, 2009), a brief overview is provided here. Figure 1 shows a stylized industry-by-industry input-output table depicting three industries-industry 1 , industry 2 , and industry 3 -in which each entry represents the value of transactions taking place in a single 12-month period. The rows and columns have distinct meaning: reading down an industry column shows the value of inputs by each industry used in producing the column industry's output; gross income makes up the gross regional product including payments for labor, indirect business taxes, and proprietors' income; and IM is the value of imported intermediate goods not supplied locally. Reading across the industry row depicts the value of purchases made by each industry in the production of their respective goods. Final demands, $Y$, are the value of purchases for local consumption, and $E X$ is the value of industry exports to the rest of the 


\begin{tabular}{|c|c|c|c|c|c|c|}
\hline & Industry 1 & Industry 2 & Industry 3 & $\begin{array}{c}\text { Final } \\
\text { Demand }\end{array}$ & $\begin{array}{l}\text { Rest of } \\
\text { World }\end{array}$ & $\begin{array}{c}\text { Gross } \\
\text { Output }\end{array}$ \\
\hline Industry 1 & $X_{11}$ & $X_{12}$ & $X_{13}$ & $Y_{1}$ & $E X_{1}$ & $X_{1}$ \\
\hline Industry 2 & $X_{21}$ & $X_{22}$ & $X_{23}$ & $Y_{2}$ & $E X_{2}$ & $X_{2}$ \\
\hline Industry 3 & $X_{31}$ & $X_{32}$ & $X_{33}$ & $Y_{3}$ & $E X_{3}$ & $X_{3}$ \\
\hline Gross income & $V_{1}$ & $V_{2}$ & $V_{3}$ & & & V \\
\hline Rest of world & $I M_{1}$ & $I M_{2}$ & $I M_{3}$ & & & \\
\hline Gross payments & $X_{1}$ & $X_{2}$ & $X_{3}$ & $Y$ & & $X$ \\
\hline
\end{tabular}

Figure 1. Representative Input-Output Table

world. The gross output for each row must equal the gross payments of the corresponding column, indicating that every purchase is someone else's sale.

Returning to the data logger example, for a select region represented by the input-output table, the interindustry transactions $X_{i j}$ depict the sum of all data logger records of the value of sales of good $i$ to industry $j$, the value of local purchases of industry $i$ output $\left(Y_{i}\right)$, the value of exported sales $\left(E X_{i}\right)$, and total value of output $\left(X_{i}\right)$ that occur in the model region. The portion of industry output that remains in the local economy is total output minus exports $\left(X_{i}-\right.$ $\left.E X_{i}\right)$. Because industry $j$ uses industry $i$ output in production, when measuring the contribution of industry $i$ to the local economy, care should be taken to recognize industry $i$ 's contribution to industry $j$ 's output. These corelationships across sectors can be calculated using the input-output table, as will be shown via example.

Consider an example within the local foods framework. The intent is to measure the total economic value of local food where "local food" is defined as food that is grown in the region and that remains within the region for consumption (here region is implicitly defined by the level of data used, e.g., state or county). This is a much broader definition of local food than is generally conveyed by proponents of local food systems (Martinez et al., 2010). Here food distributed through conventional channels is included in the local food measures as long as it remains in the region from farm to plate. For example, suppose that industry 1 is apple production and represents the totality of the regional farm-food production; industry 2 is manufacturing, including the production of applesauce; and industry 3 entails all retail trade sectors that include transportation, wholesale, and retail transactions. The effort is to quantify the total value of local foods as measured by transactions for apples that are grown in the region and remain in the region through to consumption as fresh apples and processed applesauce.

From Figure 1, the total value of local apple sales in the region is total output minus exports. Household and institutional purchases of apples are included in $Y_{1}$, and apple purchases of other apple producers and food manufacturers are 
captured in $X_{11}$ and $X_{12}$, respectively. ${ }^{1}$ The value of apple producers' purchases from other apple producers, which includes one-for-one transactions to meet contractual deliveries, the purchase of services, and the purchases of inputs, is recorded by $X_{11}$. Some researchers may be tempted to exclude such transactions from the total value of output to avoid double counting of purchases of finished apples across growers (Canning, 2011), but this would also net out the value of services and inputs used in making apples for final uses.

The food processor sector buys $X_{12}$ in value of fresh apples. As shown in the columns of the input-output table, industry 2 also purchases other inputs like packaging, energy, sugars, cinnamon, and other ingredients that go into the final value of processed apples sold. They combine these purchases with labor income in hopes of generating value added in excess of the costs of ingredients, processing, and marketing activities. It is not unreasonable to recognize that fresh apple inputs should claim a share of this value added generated in processing. Estimating the value added of food manufacturing attributed to the local apple value chain can be accomplished in two steps: (1) estimating apples' share of the value added in food manufacturing and (2) estimating the share of food manufacturing that remains local. For industry 2 , apple inputs' share of value added can be calculated as $X_{12}$ divided by the sum of intermediate inputs $X_{12}$, $X_{22}, X_{32}$, and intermediate imports $I M_{2}$. Multiplying this with the value-added term, $V_{2}$, provides apples' share of the food manufacturing value added. The share of food manufacturing value added that remains in the region is calculated as the sum of $X_{21}, X_{22}, X_{23}$, and $Y_{2}$ divided by $X_{2}$, the gross output of industry 2 . Multiplying this by apples' share of the food manufacturing value added provides an estimate of the value chain of local apples through processing.

Finally, we can recognize local food's role in trade channels represented by the row and column labeled industry 3. First, we should recognize that the trade sector records the margins earned by this sector rather than how much the trade sector purchases for resale (Isard et al., 1998). Margins are roughly analogous to markups that retailers and wholesalers charge and transportation and warehousing fees. Trade and transportation sectors have a special treatment in input-output tables in that the values represent margins earned on the trade or transport of the corresponding commodities. For example, $X_{13}$ measures the margins earned by transport sectors in shipping and those earned by wholesale and retailers in handling apples. Margins earned for handling imported apples are captured by $I M_{3}$. Therefore, local apples' share of trade margins are captured by the margins earned from handling fresh, local apples and from handling processed apples (i.e., applesauce in the example). The first is simply the value of the entry $X_{13}$, whereas the second is apples' share of $X_{23}$. Local apples' share of

1 Trade sector values, $X_{13}$, have a different interpretation because apples purchased by households through retail trade sectors are accounted for in $Y_{1}$, but only the trade and transportation margins earned by the trade sector are recorded in $X_{13}$. 
manufacturing trade margins can be calculated as the share of industry 2 output derived from local apple inputs. That is, the value of apple inputs and apples' share of value added calculated in the prior step and divided by $X_{2}$, gross output. Multiplying this by total margins earned from manufacturing, $X_{23}$, and adding apple margins, $X_{13}$, gives the value of trade activities of the local apple sector.

These calculations are summarized in the following equations:

$$
\begin{gathered}
\text { Local direct sales }=X_{11}+X_{12}+Y_{1} \\
\text { Local processed VA }=\left(\frac{X_{12}}{\sum_{i-1}^{3} X_{i 2}+I M_{2}} V_{2}\right)\left(\frac{X_{2}-E X_{2}}{X_{2}}\right) \\
\text { Local trade }=X_{13}+\left(\frac{X_{12}+\text { local processed VA }}{X_{2}}\right) X_{23},
\end{gathered}
$$

where the sum of local direct sales, local processed VA (value added), and local trade gives the total value of the local food system as exemplified in this simplified example. In practice, there will be many segments of the local food industry, but the same approach applies.

\section{Empirical Example with Michigan Data}

We use the approach described previously to estimate baseline values of the size of Michigan's local food sector using Michigan data in IMPLAN 3.0 (Minnesota IMPLAN Group [MIG], 2010). IMPLAN is an economic impact estimation tool used throughout the United States. Within IMPLAN is a complete input-output structure for the selected economy, down to the county level. County-level data can be aggregated into multicounty regions, allowing the user a great deal of latitude in designing the modeling region. The IMPLAN sectors currently total 440 distinct industries/commodities, in which 16 sectors represent agricultural production sectors, including both food- and nonfood-producing segments. The industry rows inform the relevant production sectors that largely purchase intermediate food inputs from growers. Although using IMPLAN to model economic impacts is a relatively routine exercise for agricultural economists, exploring the underlying data requires some time investment by the user.

To facilitate calculation, we create two aggregate sectors as shown in Table 1 . The first industry aggregate, food production, includes the food-related agricultural sectors. ${ }^{2}$ The second aggregate, food processing, constitutes all foodprocessing/manufacturing sectors. Animal food processing is included for both

2 Commercial hunting and trapping is included as a food production industry because Michigan Department of Natural Resources, Wildlife Conservation Order allows for the sale of game carcasses for food consumption if lawfully gained. 
Table 1. IMPLAN Commodity Aggregated Sectors

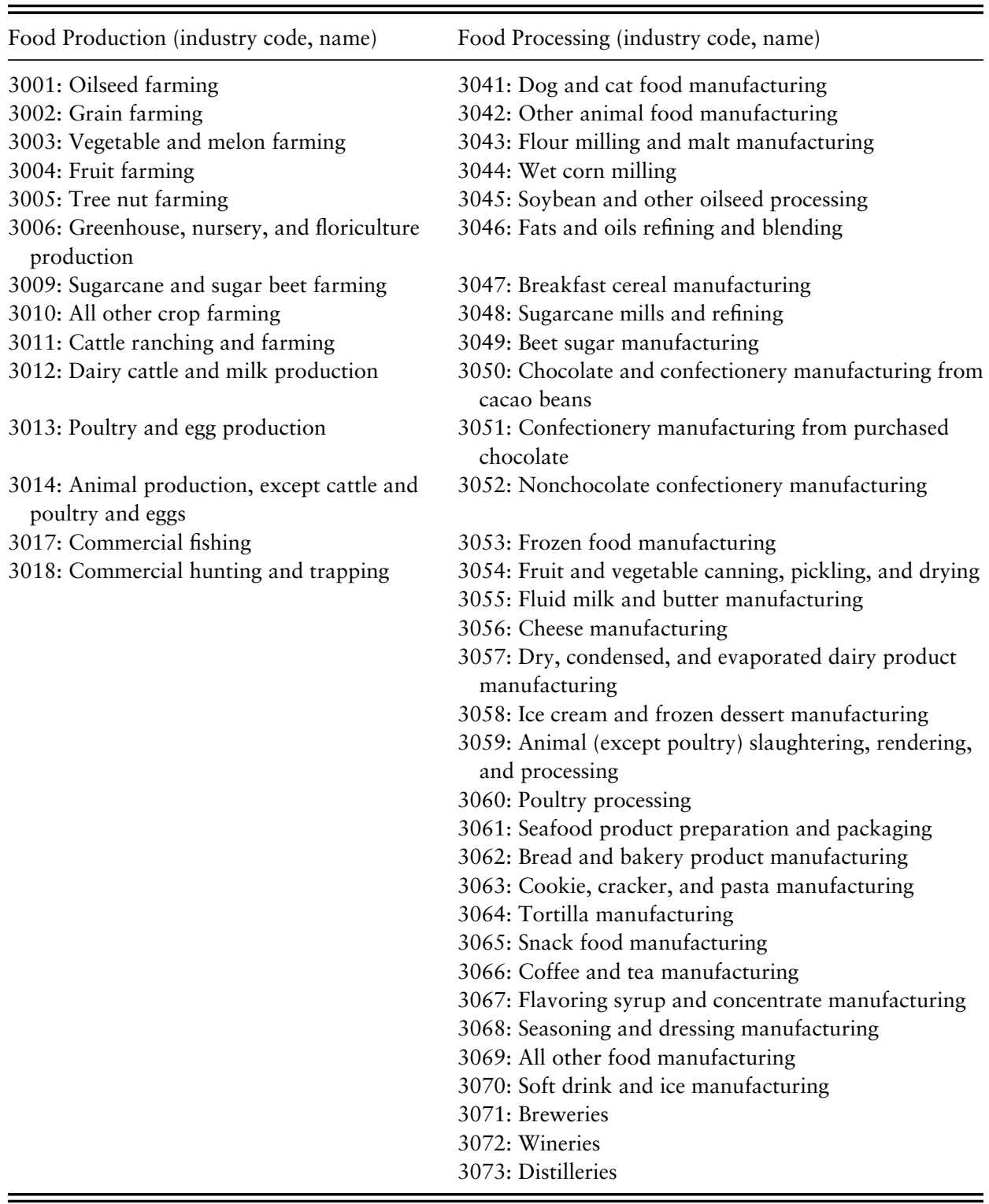

the inclusiveness of local food production and to recognize the local values of livestock feed along the production chain. Some processing sectors, especially coffee and tea manufacturing, may appear out of place in a region like Michigan. The extents to which such sectors do not buy inputs from local farms are revealed by the absence of local transactions for such goods. Similarly, the extent to which 
secondary agricultural inputs from local producers are added, like flavorings, will also be revealed through the transactions table.

The remaining sectors were left unaggregated to facilitate tracking purchases. Aggregation reduces the level of detail necessary in measuring transactions across industries but does not alter the final value of transactions and is recommended for reducing the data requirements of this approach, though more detailed descriptions of the underlying transactions by commodity are possible without aggregation.

Although all transactions in IMPLAN are recorded in dollar values of output (gross sales), values in terms of jobs and regional income can also be derived. The standard approach to converting sales into employment and earnings in input-output modeling is to generate fixed ratios of employment and earnings, respectively, per dollar of sales. IMPLAN provides several measures derived from various government reporting agencies for developing such ratios, including employment and three measures of earnings-namely, employee wages, proprietary income, and nonemployment income (MIG, 2010).

We break local food consumption into three broad categories: households, food service, and institutions. Households represent at-home consumption of Michigan grown and processed foods purchased at consumer prices. Food service entails purchases of Michigan grown and processed foods at the price paid by the food service industry. It includes all food and drinking establishments, recreation establishments, and accommodation services. It also includes retail establishments by which consumers traditionally purchase food products, such as food and beverage retail stores and convenience stores, but also other retail establishments where food sales may take place but do not make up the primary service. Such fringe outlets for food sales are included for inclusiveness of tracking local food transactions, capturing convenience purchases and the sales of novelty snack-goods specific to the region. The transactions table allows for the separation of food sales from other sales for all sectors. The final consumption category is that of institutions, which entails local purchases at institutional purchase prices. This includes all local federal government expenditures for military and social programs (including the USDA Commodity Supplemental Food Program, the National School Lunch Program, and others) and state and local government expenditures (mostly composed of social programs, primary and secondary education, and public hospital expenditures). Additionally, the institutions category includes purchases by private hospitals, residential care facilities, and educational facilities, as well as social services organizations. A complete breakdown of consumption categories along with their respective IMPLAN sector codes is provided in Table 2. All other IMPLAN sectors remained disaggregated.

There is a material reason for using purchase prices as the basis of sales for nonhousehold purchasers. Household prices represent final consumer prices. Because we end the local value chain for food service and institutional 
Table 2. Consumption Categories

\begin{tabular}{|c|c|c|}
\hline Households & Food Services & Institutions \\
\hline 10001: Households <10k & 3007: Spectator sports companies & $\begin{array}{l}\text { 11001: Federal government } \\
\text { nondefense }\end{array}$ \\
\hline 10002: Households $10-15 \mathrm{k}$ & $\begin{array}{l}\text { 3007: Museums, historical sites, } \\
\text { zoos, and parks }\end{array}$ & $\begin{array}{l}\text { 11002: Federal government } \\
\text { defense }\end{array}$ \\
\hline 10003: Households 15-25k & $\begin{array}{l}\text { 3007: Fitness and recreational } \\
\text { sports centers }\end{array}$ & $\begin{array}{l}\text { 12001: State/local government } \\
\text { noneducation }\end{array}$ \\
\hline 10004: Households 25-35k & 3007: Bowling centers & $\begin{array}{l}\text { 12002: State/local government } \\
\text { education }\end{array}$ \\
\hline 10005: Households 35-50k & $\begin{array}{l}\text { 3007: Amusement parks, arcades, } \\
\text { and gambling industries }\end{array}$ & 3397: Private hospitals \\
\hline 10006: Households 50-75k & $\begin{array}{l}\text { 3007: Other amusement and } \\
\text { recreation industries }\end{array}$ & $\begin{array}{l}\text { 3398: Nursing and residential } \\
\text { care facilities }\end{array}$ \\
\hline 10007: Households 75-100k & $\begin{array}{l}\text { 3007: Hotels and motels, } \\
\text { including casino hotels }\end{array}$ & $\begin{array}{l}\text { 3391: Private elementary and } \\
\text { secondary schools }\end{array}$ \\
\hline 10008: Households 100-150k & 3007: Other accommodations & $\begin{array}{l}\text { 3392: Private junior colleges, } \\
\text { colleges, universities, and } \\
\text { professional schools }\end{array}$ \\
\hline \multirow[t]{13}{*}{ 10009: Households 150k+ } & $\begin{array}{l}\text { 3007: Food services and drinking } \\
\text { places }\end{array}$ & $\begin{array}{l}\text { 3393: Other private } \\
\text { educational services }\end{array}$ \\
\hline & $\begin{array}{l}\text { 3320: Retail stores-motor vehicle } \\
\text { and parts }\end{array}$ & 3399: Child day care services \\
\hline & $\begin{array}{l}\text { 3321: Retail stores-furniture and } \\
\text { home furnishings }\end{array}$ & $\begin{array}{l}\text { 3400: Individual and family } \\
\text { services }\end{array}$ \\
\hline & $\begin{array}{l}\text { 3322: Retail stores-electronics } \\
\text { and appliances }\end{array}$ & $\begin{array}{l}\text { 3401: Community food, } \\
\text { housing, and other relief } \\
\text { services }\end{array}$ \\
\hline & $\begin{array}{l}\text { 3323: Retail stores-building } \\
\text { material and garden supply }\end{array}$ & 3423: Religious organizations \\
\hline & $\begin{array}{l}\text { 3324: Retail stores-food and } \\
\text { beverage }\end{array}$ & $\begin{array}{l}\text { 3425: Civic, social, } \\
\text { professional, and similar } \\
\text { organizations }\end{array}$ \\
\hline & $\begin{array}{l}\text { 3325: Retail stores-health and } \\
\text { personal care }\end{array}$ & \\
\hline & $\begin{array}{l}\text { 3326: Retail stores-gasoline } \\
\text { stations }\end{array}$ & \\
\hline & $\begin{array}{l}\text { 3327: Retail stores-clothing and } \\
\text { clothing accessories }\end{array}$ & \\
\hline & $\begin{array}{l}\text { 3328: Retail stores-sporting } \\
\text { goods, hobby, book, and music }\end{array}$ & \\
\hline & $\begin{array}{l}\text { 3329: Retail stores-general } \\
\text { merchandise }\end{array}$ & \\
\hline & 3330: Retail stores-miscellaneous & \\
\hline & $\begin{array}{l}\text { 3331: Retail nonstores-direct } \\
\text { and electronic sales }\end{array}$ & \\
\hline
\end{tabular}


consumption at the point of acquisition by food service and institutions, rather than at the point of sale to the final consumer, the vendor prices are used. For food service, our analysis does not posit that restaurant jobs serving local food are part of the local food value chain. For example, restaurants that serve locally sourced foods add value to unprocessed food inputs and sell the final product with markup. One could argue that the local food gave rise to an enhanced value added by the restaurant and therefore should be considered part of the value chain of local food. However, it would be difficult to account for the component of value added that is attributed to the unprocessed food input rather than from other value-added activities. In addition, one has to be careful to separate out the value of the actual food from the value of the other services provided by the food service sector. For example, consider the IMPLAN output for amusement parks where food consumption is only one component of the total expenditures. We consider the value of the amusement park purchases for food commodities at prices paid by the park, not the price the consumer pays for it. As a result, we elected to assume that the value chain ends when the commodity is sold to the food service provider. Although this will have a modest effect of underestimating the total food system impact, we consider this preferable to overestimating the impact. Finally, to facilitate the narrative, we assume local foods have two channels to consumers. The first channel omits foodprocessing sectors (manufacturing). This includes direct-to-consumers sales and unprocessed foods sold in retail (and provided through institutions). The second channel is through food-processing sectors.

\section{Results and Discussion}

We use the IMPLAN commodity balance reports for estimating the transaction flows across the two industry aggregates, food production and food processing, and the consumption categories. The flow from agricultural production to consumption, as modeled in the IMPLAN data, is shown in Figure 2. Starting with the food production aggregate made up entirely of food-related agricultural sectors, IMPLAN reports that in 2009 the total state level of agricultural output was $\$ 5.67$ billion. This compares favorably with USDA, Economic Research Service (2013) estimates of 2009 Michigan food agriculture output of $\$ 5.79$ billion. Approximately $\$ 3.13$ billion was directly exported out of the state, and $\$ 2.51$ billion remained local. For the $\$ 2.51$ billion worth of unprocessed agricultural foods, $\$ 1.54$ billion was sold to processors, and $\$ 645.9$ million was sold to households, food service industries, or institutions providing food services. The remaining $\$ 328.7$ million was sold through other channels for which the nature and location of final consumption is not easily discernable. These are transactions to sectors not included in the aggregate food-processing sector shown in Table 1 or in the consumption categories shown in Table 2. 


\section{Consumption of Locally Produced Food $=\mathbf{\$} 2.82$ billion}

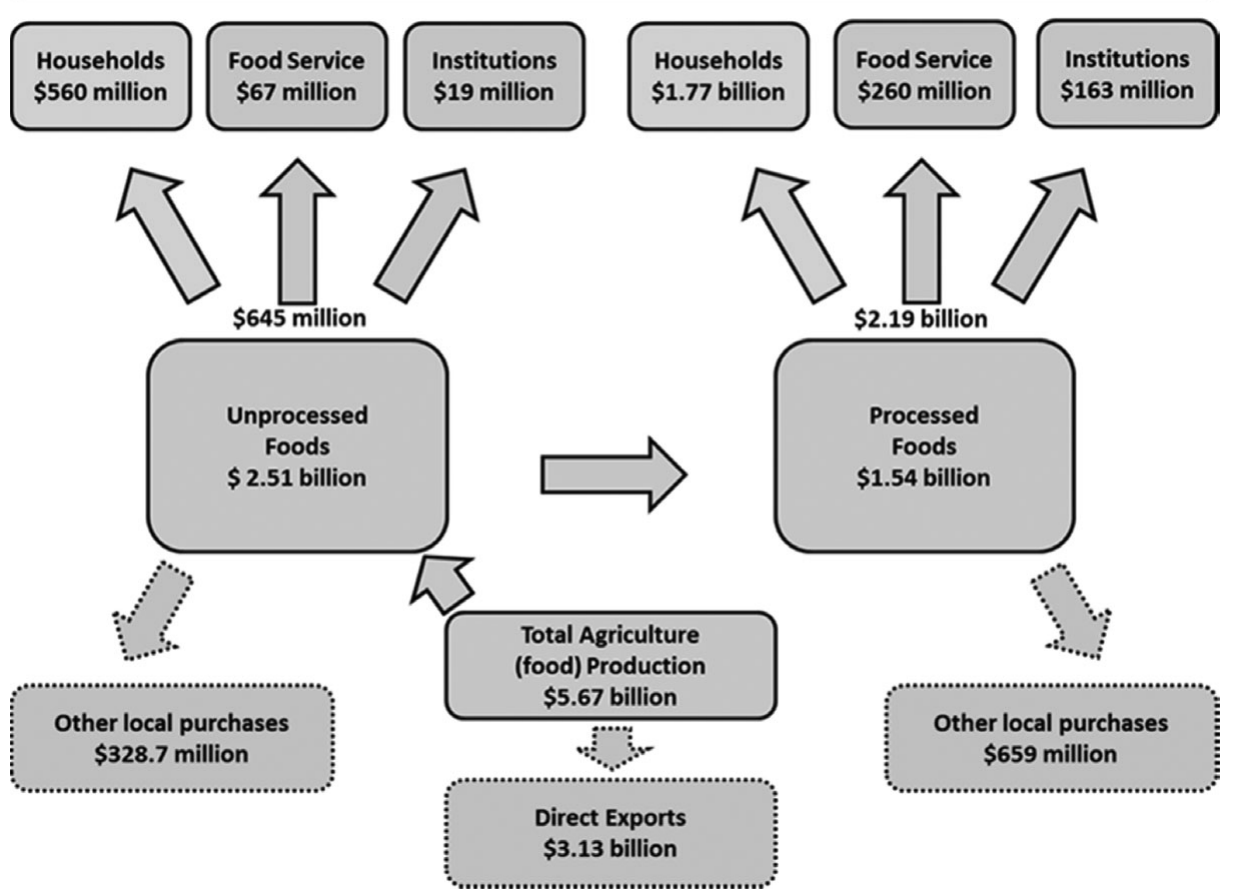

Figure 2. 2009 Sales Value of Michigan Local Food Chain (source: authors' calculations based on IMPLAN 2009 Michigan data)

The unprocessed channel consists of consumption of unprocessed foods including direct household consumption, food service purchases, and institutional purchases. Households purchase unprocessed food through direct purchases from farms via farmers markets, CSA enterprises, and roadside stands, but also through intermediated purchases at retail outlets where unprocessed produce is sold. We estimate that approximately $\$ 560$ million of household expenditures for unprocessed foods came from Michigan agricultural producers in 2009. Food service purchases of locally sourced, unprocessed food totaled $\$ 67$ million. This is measured in the price food service businesses paid, rather than the value they sold to their customers. Finally, institutional purchases totaled $\$ 19$ million in 2009 .

Unprocessed foods channeled through food processers are subject to price markups before final purchase for consumption. This markup represents payments to labor, capital owners, and indirect business taxes, as well as the value of inputs that go into processing foods, including energy, packaging, other food imports, and other inputs required to process foods to final goods for delivery to retail establishments or direct sales for household consumption, 
food service, and institutional purchases. IMPLAN's commodity balance sheet is used to generate the statewide value of processed foods transactions. However, because a sizeable portion of Michigan processed foods come from imported raw foods, only the proportion made up of locally sourced inputs should be used. Therefore, an assumption is made that the contribution of the locally processed food items' value is equal to the proportion of food inputs made from locally sourced unprocessed food. This is measured in the regional purchase coefficient (RPC) provided by the IMPLAN software, in which the RPC measures the share of purchases that are supplied locally and is based on local availability.

Although food processors purchase \$1.54 billion in Michigan-supplied unprocessed food, IMPLAN estimated that total sales of Michigan processed food was $\$ 36.6$ billion in 2009. This includes sales to other food processors, service providers, households, and for export. However, we are only concerned with those sales made up of locally sourced inputs that remained local. Hence, processed foods that are eventually exported are excluded. IMPLAN's estimated RPC suggests that approximately 35.7\% of Michigan's unprocessed agricultural food product demand was sourced from Michigan producers in 2009. Alternatively, the RPC for processed food was estimated at $34.9 \%$. This suggests that approximately $12.5 \%(=0.357 \times 0.349 \times 100)$ of final consumption of processed food in Michigan is made up of locally sourced food. This ratio is constant across all sales, whether they are made to households, food service, institutions, or other processers.

The second channel to consumption (Figure 2) indicates $\$ 1.54$ billion in Michigan-sourced unprocessed food products went to Michigan processors. Raw inputs are combined with value-added processing before being sold as processed foods. Only Michigan sales arising from locally sourced raw inputs that are processed locally are counted toward the total value of local food sales. As depicted in Figure 2, household purchases of locally processed foods generated $\$ 1.77$ billion in total sales. For food service and institutional purchases, the values of locally sourced processed foods total $\$ 260$ million and $\$ 163$ million, respectively. Similar to unprocessed foods, the value of food service and institution sales is set at the point of sale from the processor so as not to count the value added by food preparation at restaurants or institutions. In total, the value of locally sourced foods was approximately \$2.20 billion for Michigan in 2009 . Other in-state transactions for processed foods were observed that totaled $\$ 659$ million, but these transactions do not fall into the consumption categories shown in Table 2, and the nature of these transactions put into question their role in the local food chain. They are therefore excluded from the final calculations.

Combining processed and unprocessed food consumption in Michigan, locally sourced food comprised approximately $\$ 2.82$ billion in 2009. Although food production agricultural sales totaled approximately $\$ 5.67$ billion in 2009 , approximately $55.7 \%$ was exported, whereas the remaining $44.3 \%$, or $\$ 2.51$ billion, was delivered within the state. Our best estimate is that in 2009 sales for 
Table 3. Estimated Local Share of Michigan Food Purchases

\begin{tabular}{lllll}
\hline \hline Description & \$ Billions & $\begin{array}{l}\text { \% of Total Local } \\
\text { Food Sales }\end{array}$ & $\begin{array}{l}\text { IMPLAN } \\
\text { RPC }\end{array}$ & $\begin{array}{l}\text { Regional Purchase } \\
\text { Shares }\end{array}$ \\
\hline Processed food & 2.20 & 77 & $34.90 \%$ & $12.50 \%$ \\
Unprocessed food & 0.65 & 23 & $35.70 \%$ & $35.70 \%$ \\
$\begin{array}{l}\text { Totals } \\
\text { Weighted average share }\end{array}$ & 2.84 & & & $17.70 \%$ \\
\hline \hline
\end{tabular}

a Calculated as the RPC $\times$ (regional-sourced input).

Note: RPC indicates regional purchase coefficient.

consumption of Michigan-sourced unprocessed foods totaled $\$ 0.65$ billion, and sales for consumption of Michigan-sourced processed foods totaled \$2.2 billion. This values 2009 local food sales at $\$ 2.85$ billion, suggesting that farm sales to intermediaries make up a significant portion of the local food system value.

The values shown in Figure 2 can be used to estimate the share of Michigan agricultural output that remains in the state economy through to consumption. As shown in Table 3, unprocessed local foods make up approximately $\$ 0.65$ billion in total local food sales, whereas processed local foods make up approximately $\$ 2.20$ billion. Hence, unprocessed foods make up approximately $23 \%$ of total local food sales, and processed foods make up the remaining $77 \%$. The estimated RPCs suggest that approximately 35.7\% of Michigan's agricultural production sales remain in the state, and processors purchase $34.9 \%$ of their agricultural inputs from suppliers within the state. When combining unprocessed and processed foods for local consumption, we estimate that approximately $17.7 \%{ }^{3}$ of Michigan's food consumption arises strictly through local supplies and is below the $20 \%$ goal of the Michigan Good Food Charter for 2020.

In the estimates in Table 3, the RPCs are paramount in determining what share of intermediate and final demands are filled by locally sourced agricultural foods, and shifts in consumer purchases toward local foods are expressed through changes in the RPCs. Should consumers and processors increase their share of unprocessed food purchases made up of local foods, the RPC for unprocessed food will increase, and a larger share will remain within the local economy through consumption. We can estimate how much the RPC of agrifood production must increase to reach the $20 \%$ target of the Michigan Good Food Charter. This exercise can also be used to demonstrate how sensitive our procedure is to changes. Consecutively increasing the unprocessed food RPC from $35.7 \%$ until the share estimate of $17.7 \%$ reaches $20 \%$ shows that increasing the unprocessed foods sector RPC to $40.2 \%$ would allow for meeting the Michigan Good Food Charter objective of $20 \%$ by 2020 . From a perspective

3 Calculated at the weight regional purchase shares as $0.77 \times 12.5+0.23 \times 35.7$. 
Table 4. Estimated Local Share of Michigan Food Purchases under Higher Agri-Food Regional Purchase Coefficient (RPC)

\begin{tabular}{lllll}
\hline \hline Description & \$ Billions & $\begin{array}{l}\text { \% of Total Local } \\
\text { Food Sales }\end{array}$ & $\begin{array}{l}\text { IMPLAN } \\
\text { RPC }\end{array}$ & $\begin{array}{l}\text { Regional Purchase } \\
\text { Shares }^{\mathrm{a}}\end{array}$ \\
\hline Processed food & 2.48 & 77 & $34.9 \%$ & $14.0 \%$ \\
Unprocessed food & 0.73 & 23 & $40.2 \%$ & $40.2 \%$ \\
Totals & 3.20 & & & $20.0 \%$ \\
Weighted average share & & & & \\
\hline \hline
\end{tabular}

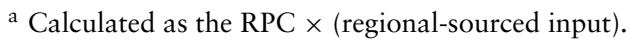

of the sensitivity of the estimates to the RPC, for every $1 \%$ increase in the agrifood sector RPC, the local share of expenditures increased by $0.51 \%$ and the total value of local foods by approximately $\$ 80$ million. This reflects both the increased demand for final consumption and increased intermediate purchases of locally sourced food and assumes that the RPC of processed foods remains unchanged. In practice, consumers may be driven to increase the share of processed foods they consume that come from local sources as well.

Table 4 shows the resulting calculations, indicating that increasing the RPC for unprocessed foods increases the total purchases of both locally sourced processed and unprocessed foods. Unprocessed food sales increase in response to increased purchases for final consumption and intermediate purchases for locally sourced unprocessed foods, and locally sourced processed food sales increase because the share of final demands that contain locally sourced food increases. Finally, the regional purchase shares increased to $14.0 \%$ for processed foods and $40.2 \%$ for unprocessed foods.

The estimates provided in this study can also be used to estimate the economics of local foods for other years based on the 2009 input-output table. If the structure of transactions largely remains unchanged over time, estimates can be extrapolated based on fixed ratios. Assuming RPCs remain constant from the 2009 benchmark year, the value of the local food system can be updated with 2011 USDA Michigan food agriculture output estimates. This assumption is most likely to hold within short intervals from the benchmark year but may result in biased estimates under certain conditions and over longer time periods. If exports are considered a residual secondary market, such that local markets are satisfied before exporting, extrapolation to other years may lead to unbiased estimates. This is the general tenet of traditional approaches to estimating RPCs. However, if local demand is considered the residual market and exports as the primary market, this assumption will inflate the expected values if agricultural output increases and understate them if it declines. The logic follows. If production increases to meet export demand only, then the local food chain should not be affected by the increase in output. This assumption can be tested with consecutive 
models and interviews with processers to assess how RPCs respond to changes in agricultural output.

Table 5 shows the 2011 estimated values of locally sourced, processed, and consumed foods in Michigan by using 2011 USDA output estimates. This is based on agricultural food production output of $\$ 9.03$ billion (USDA, Economic Research Service, 2013). The structure of Table 5 follows that of Figure 2, breaking out unprocessed foods from processed foods. However, it also adds estimates in terms of employment and earnings based on IMPLAN's estimated employment and earnings ratios to output, by sector. ${ }^{4}$ In total, it is estimated that the local food system generated $\$ 4.53$ billion in total Michigan output, supporting 18,627 jobs with total earnings of \$680.5 million in 2011.

\section{Weakness of Regional Input-Output Tables in Measuring the Local Food System}

We started this analysis with a depiction of an ideal method for estimating local food system economics. Accepting that such a method is not broadly feasible, we then looked at input-output economics as the next best alternative strategy that has analogous underpinnings to our ideal method. Although a fairly broad view of input-output economics was considered, the discussion largely smoothed over significant details that undermine efforts to get precise estimates of the size of the local food economy.

The most critical weakness of regional input-output tables is the paucity of transactions data at the regional level. Although IMPLAN provides an easily accessible industry-by-industry table of the selected region, the harmony of that table masks a much more complex effort to develop regional input-output tables. Regional economists have derived shortcut methods of developing regional inputoutput tables from national tables. Such methods of regionalizing the national input-output table have been a primary occupation of regional economists, and a comprehensive discussion of this effort was presented by Jeffrey Round (1983). Approaches generally start with the national input-output table regionalized to fit the local economy using RPCs.

RPCs are estimates of the availability and use of locally sourced goods and are estimated by commodity for each selected modeling region. They indicate the proportion of intermediate and final demands satisfied by local production. For example, an RPC of 0.60 for apple farming indicates that $60 \%$ of food manufacturing's purchase of apples comes from local suppliers. It also means that $60 \%$ of the apple purchases for home consumption (not processed) are supplied by local farms. IMPLAN estimates RPCs based on the underlying model data, where the RPCs are a measure of expected purchases relative to local production

4 Aggregation of sectors may bias these ratios. Consider that there is only one ratio of employment to food manufacturing output used in this estimate, but underlying this detail are 33 food manufacturing sectors, each with unique sets of ratios. See Miller and Blair (2009, p. 165) for more details. 
Table 5. Economic Value of Michigan Locally Produced, Processed, and Consumed Foods

\begin{tabular}{|c|c|c|c|c|c|c|c|}
\hline $\begin{array}{l}\text { Sales/Output } \\
\text { Employment } \\
\text { Earnings }\end{array}$ & $\begin{array}{l}\$ 4,526,239,495 \\
18,627 \\
\$ 680,467,182\end{array}$ & & & & & & \\
\hline Earnings & Households & Food Service & Institutions & & Households & Food Service & Institutions \\
\hline Sales/Output & $\$ 891,904,238$ & $\$ 105,964,965$ & $\$ 30,745,879$ & & $\$ 2,824,061,688$ & $\$ 413,443,122$ & $\$ 260,119,604$ \\
\hline Employment & 10,580 & 1,257 & 365 & & 5,187 & 759 & 478 \\
\hline \multirow[t]{3}{*}{ Earnings } & $\$ 328,029,392$ & $\$ 38,972,371$ & $\$ 11,307,887$ & & $\$ 243,968,880$ & $\$ 35,717,086$ & $\$ 22,471,566$ \\
\hline & $\uparrow$ & $\uparrow$ & $\uparrow$ & & $\uparrow$ & $\uparrow$ & $\uparrow$ \\
\hline & & $\begin{array}{l}\text { Unprocessed Foods } \\
\$ 4,000,598,082\end{array}$ & & $\rightarrow$ & & $\begin{array}{l}\text { Processed Foods } \\
\$ 2,448,470,191\end{array}$ & \\
\hline
\end{tabular}


for each industry. The software provides three methods for estimating RPCs that represent a ratio of what is produced locally to what is required locally, where local requirements may not be fully representative of regional behavior. ${ }^{5}$ Because IMPLAN uses the underlying data to estimate RPCs, the reported RPCs are updated with each IMPLAN data release.

IMPLAN's regional input-output tables assume that producers and consumers have similar purchasing patterns locally as the nation. What varies by region is where those goods are sourced. Using the RPCs, orange juice producers in Michigan (if any exist) purchase the same ingredients in manufacturing, and households purchase the same per household quantity as in Florida. However, Michigan producers and consumers must import all of their oranges, whereas Florida producers and consumers largely purchase oranges supplied by their local growers. There has been some debate on the merit of using RPCs to regionalize national input-output tables. Lahr (2001) suggests that with properly specified RPCs, the resulting transactions table is mostly accurate, though he posits that improperly estimated RPCs represent the fallible components of regional inputoutput tables.

Another concern with the RPCs is that they are equally applied across all uses of the commodity. Regardless of whether it is an intermediate input in producing applesauce or a fresh apple for consuming whole, the same ratio of locally sourced to imported is assumed. Depending on the commodity, local shares of intermediate processing inputs are likely to be larger than for consumption. For example, processors seek to locate where they have low-cost access to inputs. It is for this reason that there exist no or very few orange juice packagers in Michigan. Most consumers are not cognizant of the geographic source of their purchases and are therefore less sensitive to the cost of shipping. Hence, we should anticipate that lower RPCs exist for purchases for final consumption. In summary, estimated RPCs may be unbiased in the aggregate but underestimate the share of locally sourced intermediate purchases while overstating that of final purchases.

A final potential source of weakness is the assumption of universal production functions. Although the RPCs add regional-specific characteristics to the otherwise national representation of transactions, the model still assumes that industries and households in the region purchase the same basket of inputs and consumables as the nation. This assumption was criticized by Lazarus, Platas, and Morse (2002) when they compared production functions and RPCs against a survey of industry suppliers. Their findings suggest that assuming the national transactions table is representative of local transactions is more likely to bias outcomes than RPC estimates.

These three weaknesses to regional input-output tables can be completely or partially alleviated with a cost. It is not uncommon for regional scientists

5 For a comprehensive exposé, see Isard et al. (1998). 
to combine nonsurvey approaches to estimating transactions with survey approaches to correctly increase the local representation of their model (Lahr, 1993). These partial-survey approaches start with a regionalized national inputoutput table, in which key industry transactions or RPCs are modified based on surveys. This allows greater precision of key industry linkages and better reflects local knowledge of trade by industry and household purchases, as Jablonski, Schmit, and Kay (2015) exhibited for local food considerations. The question then becomes at what price is one willing to invest to improve estimates of the economics of the local food system, and what is lost from deviating from baseline and standard metrics? Surveys are expensive and must be replicated to update baseline measures if tracked over time. Even for cases in which an initial survey is permitted, replicating such a survey to an equivalent extent may be challenging. However, the cost of augmenting a regionalized, national input-output table can be reduced by focusing survey effort on only a few key segments. Using surveys to augment the regionalized input-output table is a viable option for correcting potential deficiencies in canned estimates (Jablonski, Schmit, and Kay, 2015; Richardson, 1972).

\section{Summary and Conclusion}

Michigan has a vibrant local food system composed of Michigan-grown processed and unprocessed food that is ultimately consumed in the state. The Michigan Good Food Charter (Colasanti et al., 2010) has outlined a road map for further developing this local food system and established the goal that $20 \%$ of Michigan's food purchases will be locally sourced by 2020 . This study details the methods used to estimate the actual share of local food purchases and found that approximately $17.7 \%$ of Michigan's food purchases came from local sources in 2011 and that the local food system generated $\$ 4.53$ billion in sales, employed nearly 19,000 people, and contributed to just over $\$ 680$ million in state earnings. In our sensitive analysis, we demonstrate that the goal of $20 \%$ from local sources can be achieved by increasing the RPC for agriculture by approximately $5 \%$. However, a discussion of the specific policies and costs of such policies to reach this goal is outside the scope of this study.

The approach used to generate these estimates uses analytical tools readily available to agricultural economists. Such an analysis can be undertaken at the state level or the regional level down to the geographic region of a county. The methods described here can be applied to states and substate regions with and without a significant presence of agriculture, and the findings can be compared to other regions on a one-to-one basis. That is, the approach affords a high level of external consistency in estimates, which is important for policy discussions around local food systems.

However, it also has drawbacks. First, the approach is a broad-view assessment of the economic contribution of local food systems, and it may be 
difficult to isolate specific policy impacts as a result. For example, our method would not be able to assess the impact of an additional farmers market to a region. It is also difficult to isolate value-added contributions at the purchase for final consumption. That is, the consumer price for local consumption also entails retailer or food service markups, but discerning what share of those markups should be attributed to the local food product is difficult. In our estimates, we risk underestimating the total value of local food by not counting these consumer-side margins. Finally, the method of measuring local interindustry transactions that largely rely on a national input-output table regionalized to the local economy has some shortcomings that are well known to regional economists. Examining survey methods that increase the precision of local transaction estimates may be useful to consider in future research.

The strengths of this approach are in the objectivity of estimates, low costs of implementation, and comparability to replication in other regions and over time. This compares favorably with other studies relying solely on surveys of conventional local food channels like farmers markets, CSAs, and farms with direct sales to consumers. Such approaches omit a potentially larger component of the local food system that progresses through mainstream channels, like grocery stores, or goes through processing under a local food label. The ease of application at any geographic scale suggests the approach described here should be considered in other states and communities for developing benchmarks on the economic contribution of local food systems.

\section{References}

Bregendahl, C., and A. Enderton. 2012 Economic Impacts of Iowa's Regional Food Systems Working Group. Ames: Iowa State University, 2013.

Brown, C., and S. Miller. "The Impacts of Local Markets: A Review of Research on Farmers Markets and Community Supported Agriculture (CSA)." American Journal of Agricultural Economics 90,5(2008):1296-302.

Canning, P. A Revised and Expanded Food Dollar Series: A Better Understanding of Our Food Costs. Washington, DC: U.S. Department of Agriculture, Economic Research Service, Economic Research Report No. 114, 2011.

Colasanti, K., P. Cantrell, S. Cocciarelli, A. Collier, T. Edison, J. Doss, V. George, et al. Michigan Good Food Charter. East Lansing: C.S. Mott Group for Sustainable Food Systems at Michigan State University, Food Bank Council of Michigan, and the Michigan Food Policy Council, 2010.

Henneberry, S.R., B. Whitacre, and H.N. Agustini. "An Evaluation of the Economic Impacts of Oklahoma Farmers Markets.” Journal of Food Distribution Research 40,3(2009):6478.

Hughes, D.W., C. Brown, S. Miller, and T. McConnell. "Evaluating the Economic Impact of Farmers' Markets Using an Opportunity Cost Framework.” Journal of Agricultural and Applied Economics 40,1(2008):253-65.

Isard, W., I.J. Azis, M.P. Drennan, R.E. Miller, S. Saltzman, and E. Thorbecke. Methods of Interregional and Regional Analysis. Brookfield, VT: Ashgate, 1998. 
Jablonski, B.B.R., T.M. Schmit, and D. Kay. “Assessing the Economic Impacts of Food Hubs to Regional Economies: A Framework Including Opportunity Cost.” Working paper WP 2015-03, Ithaca, NY: Cornell University, 2015.

Lahr, M.L. "A Review of the Literature Supporting the Hybrid Approach to Constructing Regional Input-Output Models.” Economic Systems Research 5,3(1993):277-93.

—. "A Strategy for Producing Hybrid Regional Input-Output Tables." Input-Output Analysis: Frontiers and Extensions. M.L. Lahr and E. Dietzenbacher, eds. New York: Palgrave, 2001.

Lazarus, W.F., D.E. Platas, and G.W. Morse. "IMPLAN's Weakest Link: Production Functions or Regional Purchase Coefficients?" Journal of Regional Analysis and Policy 32,1(2002):33-48.

Low, S.A., A. Adalja, E. Beaulieu, N. Key, S. Martinez, A. Melton, A. Perez, et al. Trends in U.S. Local and Regional Food Systems: Report to Congress. Washington, DC: U.S. Department of Agriculture, Economic Research Service, Administrative Publication No. 68, 2015.

Low, S.A., and S. Vogel. Direct and Intermediated Marketing of Local Foods in the United States. Washington, DC: U.S. Department of Agriculture, Economic Research Service, Economic Research Report No. 128, 2011.

Martinez, S., M. Hand, M. Da Pra, S. Pollack, K. Ralston, T. Smith, S. Vogel, et al. Local Food Systems: Concepts, Impacts, and Issues. Washington, DC: U.S. Department of Agriculture, Economic Research Service, Economic Research Report No. 97, 2010.

McBratney, A., B. Whelan, T. Ancev, and J. Bouma. "Future Directions of Precision Agriculture." Precision Agriculture 6,1(2005):7-23.

Miller, R.E., and P.D. Blair. Input-Output Analysis: Foundations and Extensions. 2nd ed. Cambridge, UK: Cambridge University Press, 2009.

Minnesota IMPLAN Group (MIG). Reference Manual (Users Guide to IMPLAN Version 3.0 Software). Stillwater, MN: MIG, 2010.

Myles, A., and K. Hood. Economic Impact of Farmers' Markets in Mississippi. Starkville: Mississippi State University Extension Service, 2010.

Otto, D., and T. Varner. "Consumers, Vendors, and the Economic Importance of Iowa Farmers' Markets: An Economic Impact Survey Analysis.” Ames: Iowa State University, 2005.

Richardson, H.W. Input-Output and Regional Economics. New York: Wiley, 1972.

Round, J.I. "Nonsurvey Techniques: A Critical Review of the Theory and the Evidence." International Regional Science Review 8,3(1983):189-212.

Swenson, D. Investigating the Potential Economic Impacts of Local Foods for Southeast Iowa Analyzed. Ames: Iowa State University, 2009.

U.S. Department of Agriculture, Economic Research Service. Farm Income and Wealth Statistics, 2010. Internet site: http://www.ers.usda.gov/data-products/farmincome-and-wealth-statistics/value-added-years-by-state.aspx (Accessed September 30, 2013). 